\title{
Reforço e recuperação de estruturas de madeira
}

\section{Reinforcement and recovery of timber structures}

\author{
José Luiz Miotto $^{1}$; Antonio Alves Dias ${ }^{2}$
}

\begin{abstract}
Resumo
A preservação das estruturas de madeira constitui-se em motivo de constante preocupação, pois a sua deterioração implica, muitas vezes, em comprometimento do patrimônio histórico, além de colocar em risco a segurança do conjunto estrutural e, conseqüentemente, dos usuários. Muitos são os exemplos de igrejas, residências ou outras edificações em que essa manifestação ocorre. A técnica de reforço de peças estruturalmente comprometidas, por meio da adição de fibras naturais ou sintéticas, é uma alternativa que vem sendo pesquisada recentemente. No grupo das fibras sintéticas, incluem-se as de vidro, carbono e aramida. Por outro lado, tem sido freqüente na restauração de edifícios antigos, especialmente na Europa, o emprego de materiais que não foram disponíveis no passado, com o objetivo de alcançar benefícios estruturais, acústicos e estéticos. Sobre um piso existente de estrutura de madeira, tem sido executada uma laje de concreto, com um adequado sistema de conexão entre as partes, constituindo as chamadas estruturas mistas de madeira-concreto. Essa alternativa tem-se revelado muito viável, pois reúne uma série de conveniências relacionadas com a durabilidade e apresenta melhor desempenho mecânico que as estruturas de madeira convencionais. Neste trabalho apresenta-se o estadoda-arte do uso de fibras como reforço estrutural e das estruturas mistas de madeira-concreto. Palavras-chave: Estruturas de madeira. Reforço de estruturas de madeira. Estruturas mistas de madeira-concreto.
\end{abstract}

\begin{abstract}
Preservation of timber structures is a reason for constant concern because their deterioration often involves compromising the historical patrimony, besides endangering the safety of the structure, and consequently, of their users. Many are the examples of churches, residences or other constructions where this manifestation is a fact. The technique of reinforcing structurally endangered pieces with the addition of natural or synthetic fibers, is an alternative that has been researched. In the group of synthetic fibers, fiberglass, carbon and aramid ones are included.

\footnotetext{
${ }^{1}$ Mestre em Engenharia de Estruturas - EESC-USP, LaMEM. Email: miotto@ sc.usp.br. Av. Trabalhador São-Carlense, 400, Centro, São Carlos - SP.

2 Docente do Departamento de Estruturas da EESC-USP. Email: dias@ sc.usp.br. Av. Trabalhador São-Carlense, 400, Centro, São Carlos - SP.
}

Semina: Ciências Exatas e Tecnológicas, Londrina, v. 27, n. 2, p. 163-174, jul./dez. 2006 
On the other hand, it has been frequent in the restoration of old buildings, especially in Europe, the employment of materials that were not available in the past, aiming to achieve structural, acoustic and aesthetic benefits. On an existing timber structure floor, a concrete slab has been carried out, with an appropriate connection system among the parts, constituting the composite timber-concrete structures. This alternative has been considered as extraordinarily viable, because it gathers a series of convenience related with the durability and it presents better mechanic performance than conventional timber structures. In this work, the state-of-the-art of the use of fibers as structural reinforcement and of the timber-concrete composite structures, is presented. Key words: Timber structures. Reinforcement of timber structures. Timber-concrete composite structures.

\section{Introdução}

Inscritas na UNESCO, o Brasil conta com dezessete áreas tombadas como Patrimônios da Humanidade, sendo que seis delas acumulam grande patrimônio arquitetônico histórico. Dentre as áreas tombadas podem ser listadas: Centro Histórico de Goiás (GO), Diamantina (MG), Olinda (PE), Ouro Preto (MG), Centros Históricos de São Luis (MA) e de Salvador (BA). As diversas construções inseridas nessas áreas de patrimônio arquitetônico apresentam alguns aspectos coincidentes: as estruturas são de madeira; passaram várias décadas sem qualquer manutenção, devido à estagnação econômica da região; estiveram sujeitas ao ataque de agentes degradadores; e, atualmente, os projetos de revitalização urbanística dos centros históricos requerem mudanças de uso dos imóveis, conforme Carvalho (2005).

Além de serem submetidas a ações, as estruturas de madeira interagem com o ambiente, o que contribui para a perda de suas propriedades iniciais. $\mathrm{O}$ ataque biológico representa uma das principais causas de sua degradação, resultando em perda de massa e isso, conseqüentemente, diminui a sua resistência. Muitas tentativas para reforçar elementos de madeira têm sido relatadas na literatura. Um método muito comum consiste em usar placas de aço ou alumínio. Todavia, a principal desvantagem dos vários métodos de reforço envolvendo placas de metal é o alto risco de corrosão do reforço, particularmente quando usados em construções expostas às intempéries.
Para reabilitar os elementos estruturais de madeira, é possível optar pela substituição das peças danificadas ou pela solidarização de elementos que complementem a capacidade mecânica dos elementos estruturais comprometidos. A primeira das opções é a técnica usual, mas ela encontra limitações tais como a indisponibilidade de peças de madeira para a devida substituição, os custos elevados, o custo ambiental, a escassez dos materiais envolvidos ou, ainda, a incompatibilidade de suas características físicas. Dessa forma, a segunda alternativa torna-se atraente e no contexto dessas limitações surge a técnica de colagem de tecidos naturais e sintéticos, impregnados com resinas poliméricas, que é discutida na parte preliminar deste trabalho.

A técnica de reforço de estruturas de madeira com fibras sintéticas também está sendo aplicada em novas construções, especialmente em estruturas de madeira laminada colada (MLC). Embora a MLC apresente um grande número de vantagens, quando comparada às estruturas de madeira convencionais, mostram-se como desvantagens o seu modo de ruptura frágil e sua baixa rigidez. O pequeno módulo de elasticidade longitudinal da madeira faz com que as deformações sejam fatores limitantes no projeto das vigas de MLC. Assim, uma das soluções para se obter uma maior resistência à flexão, assim como modificar o seu modo de ruptura, consiste na utilização de reforço com fibras na face tracionada das peças.

No entanto, o emprego de fibras como reforço não resolve plenamente os problemas de deformabilidade das vigas de MLC, já que os 
acréscimos na sua rigidez são modestos. Para assegurar uma melhor performance à flexão, tem sido adotada uma técnica aprimorada ao longo do século $\mathrm{XX}$, que consiste na associação de uma laje de concreto à estrutura de madeira, resultando em compósitos conhecidos como estruturas mistas. Estudos demonstram que essa alternativa, também explicitada neste trabalho, é uma técnica muito promissora para os casos de readequação de antigas construções, especialmente naquelas em que há acréscimo de cargas na edificação. A adição de uma camada de concreto proporciona várias vantagens, dentre as quais cabe salientar os benefícios no isolamento acústico e o acréscimo significativo na rigidez da estrutura.

\section{Estruturas de Madeira Reforçadas com Fibras}

Além da função estrutural, as estruturas exercem outras funções, tal como o registro de técnicas construtivas usuais no passado, o que reforça a necessidade de preservá-las. O termo restauração estrutural refere-se ao processo de recuperação dos materiais, de sua forma e aparência, ocorrendo simultaneamente às reabilitações de estruturas em antigas construções. Tem sido usual, na reabilitação de elementos estruturais de madeira, a simples substituição dos elementos danificados, mas essa substituição vem, atualmente, encontrando limitações devido às grandes dimensões das peças antigas. Além dos custos elevados, podem ser incluídos outros fatores que limitam a simples substituição, como, por exemplo, os valores culturais das estruturas preservadas e as restrições econômicas e ambientais das espécies anteriormente abundantes e que estão presentes em grande parte das construções históricas, conforme Carvalho (2005).

Fibras naturais

$\mathrm{O}$ reforço de estruturas de madeira com fibras naturais encontra-se em fase inicial de investigação. Todavia, é indiscutível a sua importância, se consideradas as suas vantagens: abundância, biodegradabilidade e o baixo custo, quando comparadas com as fibras sintéticas. Recentemente, Carvalho (2005) realizou investigação sobre a aplicabilidade das fibras de sisal como reforço de estruturas de madeira, encontrando resultados promissores. Nesse trabalho, o autor utiliza tecidos de sisal, cujas fibras apresentam massa específica real igual a $1,59 \mathrm{~g} / \mathrm{cm}^{3}$ e resistência média à tração de $218 \mathrm{MPa}$, desde que impregnados com resinas poliméricas, como matéria-prima inovadora para a reabilitação estrutural. Sua pesquisa é justificada pela grande produção brasileira dessa fibra, que atualmente tem sido por volta de 134 mil toneladas anuais, correspondente a $40 \%$ da produção mundial. Um outro atrativo para o uso do sisal é o seu preço, correspondendo a aproximadamente $11 \%$ do preço das fibras de vidro e a $0,07 \%$ do valor das fibras de carbono. Há, ainda, outras fibras naturais que têm sido estudadas como reforços tais como a juta, o coco e o algodão.

As fibras têxteis, para serem utilizadas como reforços mecânicos em elementos estruturais de madeira, necessitam de uma matriz polimérica que as possa unir e também que permita a sua fixação ao elemento estrutural de madeira. A associação de fibras com uma matriz polimérica é denominada de compósito, que, segundo a American Society for Testing and Materials (2004), é uma substância que consiste de dois ou mais materiais, insolúveis uns nos outros, os quais são combinados para formar um material elaborado e possui certas propriedades não encontradas em seus constituintes isoladamente.

Nita (2006) comenta que os compósitos reforçados com fibras naturais são uma opção frente a fibrocimentos com amianto, devido à grande disponibilidade de fibras naturais como as de coco, sisal, bagaço de cana-de-açúcar e outras. As fibras naturais possuem a desvantagem de serem degradadas pelo meio alcalino, causando a perda de propriedades mecânicas dos compósitos, além de serem materiais higroscópicos. Esse autor estudou o uso da pozolana como alternativa para consumir o hidróxido de cálcio, proveniente da hidratação do cimento Portland, reduzindo a alcalinidade e 
contribuindo para o aumento da resistência mecânica de compósitos de cimento e fibras naturais.

Recentes pesquisas nacionais produziram resinas poliuretanas derivadas do óleo de mamona com desempenho mecânico vantajoso e variadas aplicações. Carvalho (2005) salienta que o sisal e a mamona são propostos como componentes do compósito para reforço estrutural de madeiras, substituindo os materiais usualmente derivados de recursos minerais não renováveis. $\mathrm{O}$ atual momento histórico revela a necessidade de desenvolvimento de tecnologias alternativas, minimizando o uso intenso de produtos derivados do petróleo, devido ao seu alto custo e à limitação das reservas.

Para se avaliar o efeito do reforço em vigas de madeira, que estão sujeitas preponderantemente à flexão, é comum pesquisar o acréscimo de rigidez proporcionado pelo reforço. Utilizando os compósitos de sisal-epóxi como reforços, Carvalho (2005) observou um aumento de rigidez em média de 14,2\%.

Existem várias técnicas para a aplicação do reforço em estruturas de madeira. Algumas são inadequadas para aplicação em estruturas que se encontram em serviço, considerando as particularidades e dificuldades inerentes ao canteiro de obras. A técnica de conformação mais adequada para as condições de obra é a laminação de tecidos pré-impregnados, impregnados por imersão ou, ainda, por pincelamento.

\section{Fibras sintéticas}

A idéia de materiais reforçados com fibras não é recente. No início da década de 30, fibras curtas de vidro foram adicionadas ao cimento, como reforço, nos Estados Unidos da América. Tang (1997) relata que, após a Segunda Guerra Mundial, os produtores norte-americanos começaram a utilizar fibra de vidro e resina poliéster na produção de cascos de embarcações. Nos anos 50, a indústria automotiva introduziu os materiais reforçados com fibras preliminarmente no corpo dos veículos - devido ao seu baixo peso, elevada resistência mecânica e à corrosão. A primeira aplicação desses materiais na engenharia civil ocorreu na construção de uma cúpula, em 1968, em Benghazi, Líbia.

O desenvolvimento das fibras sintéticas de elevado desempenho mecânico, bem como os respectivos tecidos obtidos a partir de seu entrelaçamento, permitiu a elaboração de materiais criados especificamente para as aplicações estruturais. Assim, surge a categoria de compósitos avançados ou de elevado desempenho, que são resultantes do avanço nas pesquisas das resinas, dos tecidos e dos processos de fabricação especialmente desenvolvidos para otimizar o desempenho mecânico desses materiais.

Os polímeros reforçados com fibras, também conhecidos pela sigla FRP (Fibre Reinforced Polymer) são materiais versáteis, que consistem de: (1) fibras sintéticas, incluindo vidro, carbono (ou grafite) e aramida (nome comercial Kevlar7), em diferentes formas, que são responsáveis pela resistência do compósito; (2) uma matriz polimérica, a qual serve para manter as fibras juntas, transferir forças para as fibras e protegê-las contra os efeitos ambientais. A Figura 1 ilustra a seção transversal de uma viga de MLC reforçada com fibra de vidro. O epóxi é o adesivo comumente utilizado para a fixação das fibras à madeira.

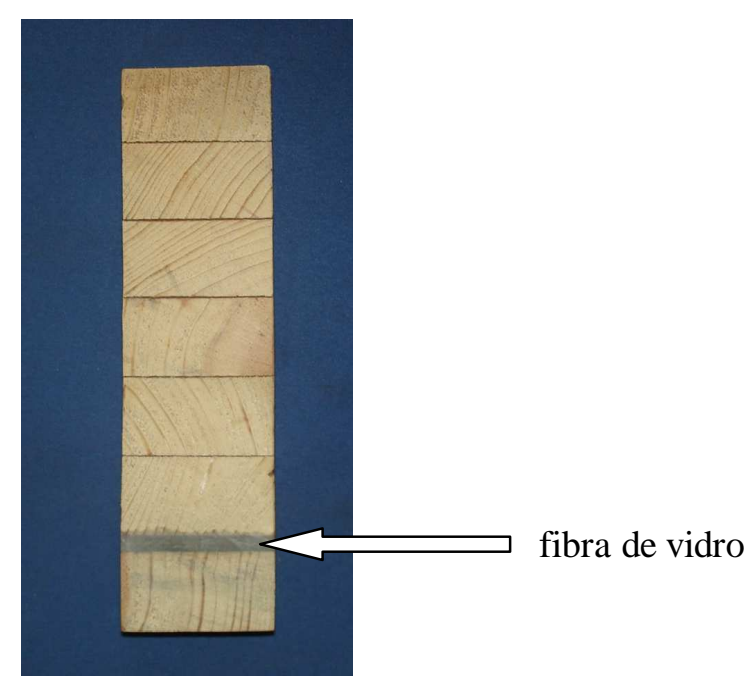

Figura 1. MLC reforçada com fibra de vidro 
Segundo Fiorelli (2002), a porcentagem máxima de fibra que deve ser utilizada em reforço de vigas de MLC é de 3,3\% em relação à altura da peça, pois, a partir desse limite, o aumento de resistência e de rigidez não é significativo. As principais características dos tecidos de fibras são listadas na Tabela 1. Embora a densidade das fibras sintéticas seja expressiva, é pequena a quantidade utilizada como reforço estrutural, de modo que não se geram problemas de acréscimo no peso próprio da estrutura. É notável, também, a elevada resistência à tração das fibras sintéticas.

Tabela 1. Características dos tecidos de fibras a $20^{\circ} \mathrm{C}$.

\begin{tabular}{l|c|c|c}
\hline \multirow{2}{*}{ Fibras } & \multicolumn{3}{|c}{ Características } \\
\cline { 2 - 4 } & $\begin{array}{c}\text { Resistência à tração } \\
(\mathrm{MPa})\end{array}$ & $\begin{array}{c}\text { Módulo de } \\
\text { Elasticidade } \\
(\mathrm{GPa})\end{array}$ & $\begin{array}{c}\text { Densidade } \\
\left(\mathrm{g} / \mathrm{cm}^{3}\right)\end{array}$ \\
\hline Fibra de vidro & 900 & 76 & 2,55 \\
\hline Orgânica (Kevlar) & 1500 & 125 & 1,44 \\
\hline Fibra de carbono & 2200 & $160-300$ & 1,75 \\
\hline Fonte: Fiorelli (2002)
\end{tabular}

Outro aspecto importante refere-se ao tipo de ruptura apresentado pelas vigas de madeira reforçadas com fibras. O reforço de fibra faz com que haja uma grande plastificação da região comprimida das vigas, causando grandes deslocamentos verticais na fase de ruptura. Dagher (2000) observou que, enquanto a ruptura à flexão de uma viga de madeira é tipicamente frágil, a correspondente ruptura de uma viga de madeira apropriadamente reforçada com fibras no lado tracionado é dúctil.

\section{MLC Reforçada com Fibras}

Se a técnica adotada na recuperação de uma estrutura de madeira requer a substituição de peças, uma alternativa para superar as limitações dimensionais da madeira serrada consiste no emprego da madeira laminada colada. A escassez das madeiras nativas também é outra justificativa para o uso da MLC e tem incentivado o desenvolvimento de pesquisas e aplicações de madeiras reflorestadas, principalmente dos gêneros Eucalyptus e Pinus.

Embora apresentem muitas vantagens em relação à madeira serrada, as vigas de MLC podem ter suas propriedades melhoradas com a colagem de reforços nas suas regiões tracionadas. Essa associação reúne as vantagens da madeira - alta performance com um custo relativamente baixo e excelente relação entre resistência e densidade - com as vantagens das fibras, tais como alta resistência e rigidez, além de versatilidade, segundo Dagher (2000).

Combinar dois materiais com propriedades físicas e mecânicas compatíveis e complementares pode revolucionar as técnicas construtivas, afirma Dagher (2000). No século XIX, a adição do aço como reforço para o concreto mudou significativamente a construção de pontes e edifícios em todo o mundo. No início do século XXI, muitos dos fatores que contribuíram para o sucesso do concreto armado são encontrados na madeira reforçada com fibras. Peças de madeira de qualidade inferior têm alta resistência à compressão e baixo custo; os FRP têm alta resistência à tração, o que compensa a baixa resistência à tração de madeira de qualidade inferior; além disso, os FRP são materiais muito flexíveis, podendo ser elaborados para assegurar compatibilidade com as propriedades da madeira.

Triantafillou e Deskovic (1992) afirmam que o uso de reforços nas estruturas de madeira, com a finalidade de melhorar as suas propriedades mecânicas, aliado a métodos de projeto mais confiáveis, permite que formas contemporâneas e avançadas de grandes estruturas (pontes de grandes vãos, por exemplo) sejam pelo menos tão confiáveis 
e economicamente competitivas como aquelas construídas a partir de outros materiais, tais como concreto armado, aço e plásticos. Salienta-se ainda a redução no consumo de madeira, pois estudos indicam uma diminuição de $30 \%$ a $40 \%$ no volume de madeira quando se utiliza a MLC reforçada com fibras, como afirma Dagher (1999).

Estudos realizados na Universidade de Maine (EUA) têm demonstrado que as fibras de vidro, aplicadas como reforço na região tracionada à uma razão de $2 \%$ a $3 \%$, podem aumentar a resistência à flexão de vigas de MLC em mais de $100 \%$ e a rigidez em $10 \%$ a $15 \%$. Os compósitos de madeira, segundo Dagher (2000), terão um significante impacto no modo de como a madeira será usada no século XXI e as razões para se combinar madeira e fibras são:

1. Aumento da resistência e rigidez.

2. Aumento da ductilidade, a qual fornece um mecanismo de ruptura seguro.

3. Melhoria das características de deformação lenta. 4. Reduzir a variabilidade nas propriedades mecânicas, o que permite utilizar valores superiores nos projetos.

5. Reduzir o efeito de volume nas vigas de MLC. 6. Utilização de madeira de qualidade inferior.

7. Melhorar a eficiência estrutural e reduzir as dimensões e pesos dos elementos estruturais;

8. Reduzir custos.

9. Reduzir as pressões no suprimento de madeira.

Esse mesmo autor ainda afirma que os compósitos de madeira com fibras podem ser bem sucedidos porque:

- As propriedades físicas, mecânicas e químicas das FRP são muito versáteis. As fibras podem ser elaboradas para tornarem-se similares e complementarem as propriedades ortotrópicas da madeira. Consequientemente, minimiza-se o problema de incompatibilidade entre a madeira e as fibras.

- As fibras reforçadas com polímeros (fibras ou matrizes) podem ser prontamente incorporadas nos processos de fabricação da MLC.
Os FRPs podem servir tanto como substitutos para as lâminas de alta qualidade, ou como materiais de reforço para as vigas de MLC. Por causa das características exclusivas da MLC - que incluem a constituição por meio de lâminas - há uma preocupação quanto à durabilidade deste compósito, pois a umidade ou a ação de meios agressivos pode degradar as propriedades tanto das fibras quanto da matriz.

Dagher (1999) também avaliou o uso de reforço com lâminas de fibras de carbono - espessura 1,5 $\mathrm{mm}$ - em vigas de MLC e, como resultado, observou que a viga sem nenhum reforço apresentou no início uma deformação lenta. No entanto, em certo momento, ocorreu uma ruptura frágil. Já com as vigas reforçadas, a ruptura frágil não ocorreu, sofrendo deformações gradativas ao longo do tempo, comprovando assim a eficiência do reforço com fibras.

A utilização de fibras como reforço de peças estruturais já vem sendo estudada no Laboratório de Madeiras e de Estruturas de Madeira (LaMEM), da Escola de Engenharia de São Carlos da Universidade de São Paulo. Fiorelli (2002) desenvolveu trabalho de investigação do comportamento das vigas maciças de madeira reforçadas com fibra de vidro e com fibra de carbono, fixadas com resina epóxi. O mesmo autor (Fiorelli, 2005) estudou as vigas de MLC reforçadas com fibra de vidro, encontrando em ambos os casos resultados satisfatórios quanto ao aumento de resistência das vigas ensaiadas. O emprego dos FRPs para reforço de elementos estruturais de madeira é uma alternativa promissora, pois se trata de um material resistente à corrosão, que proporciona um pequeno aumento do peso próprio e aumenta a confiabilidade em relação ao modo de ruptura. Porém, ressalta-se que muitos dos trabalhos publicados sobre a madeira reforçada com fibras estão focados apenas na resposta às cargas de curta duração, principalmente os que tratam de vigas de MLC. 
Aplicar o material adequado no local mais apropriado, considerando suas características físicas e mecânicas, é uma das premissas básicas do projeto ideal das estruturas contemporâneas. Certamente essa consideração conduz à utilização das estruturas mistas de madeira-concreto e aço-concreto. As vigas mistas de madeira-concreto têm sido utilizadas com sucesso em estruturas de pontes e nas edificações residenciais, industriais e esportivas, dentre outras, encontrando espaços para aplicação tanto em reparos estruturais de obras históricas como na construção de novos edifícios.

O conceito de utilização de estruturas mistas não é novo e tem sido investigado por vários pesquisadores (Pincus, 1969; Ahmadi e Saka, 1993; Gutkowski, 1996; Natterer et al., 1996; Gelfi e Giuriani, 1999). Há relatos de estruturas mistas antes da Primeira Guerra Mundial, na Inglaterra. Em 1914, a empresa Redpath Brow and Company iniciou uma série de ensaios de estruturas mistas para pisos; há registros de ensaios realizados no Canadá, em 1922, pela empresa Dominium Bridge Company. Em 1930, o sistema já estava desenvolvido e os métodos de dimensionamento estabelecidos. Entre 1922 e 1939 foram construídos muitos edifícios e pontes empregando-se esse sistema. A partir de então a técnica vem evoluindo continuamente.

A exposição direta das estruturas de madeira às intempéries é um motivo de preocupação constante, pois promove a sua deterioração e compromete a segurança dessas construções. Uma das possibilidades de amenização desse inconveniente consiste em associar à estrutura de madeira uma laje de concreto - gerando as chamadas estruturas mistas de madeira-concreto - que, além de garantir um aumento da vida útil, também é capaz de melhorar o seu comportamento mecânico. A Figura 2 mostra uma obra executada em São Paulo pela ITA Construtora e nessa obra, utilizou-se essa solução estrutural com muito êxito. As vigas espaçadas a cada $50 \mathrm{~cm}$ são de madeira serrada (Jatobá); a laje é de concreto com resistência de $30 \mathrm{MPa}$ e 4 centímetros de espessura. A ligação entre a madeira e a laje de concreto é constituída por pregos e encontra-se descrita em Alvim et al. (2000).

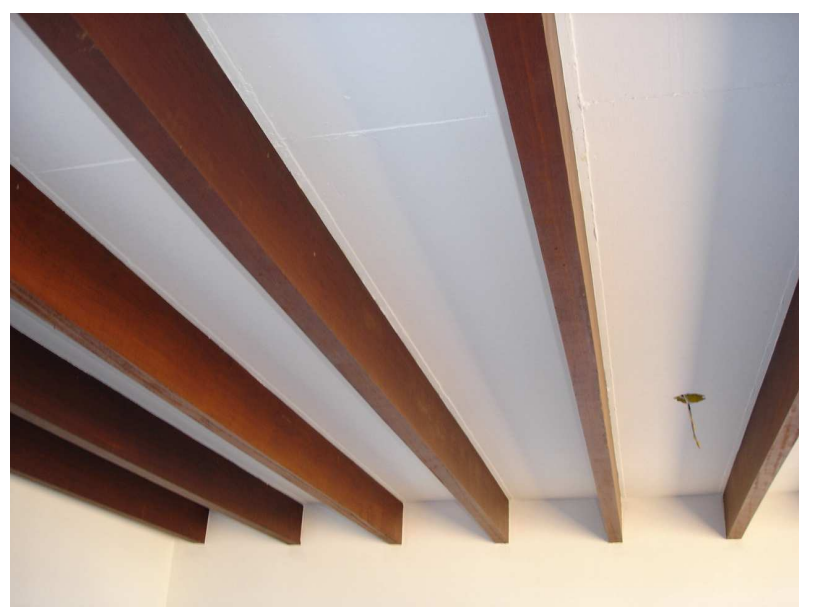

Figura 2. Estrutura mista de madeira-concreto em residência

Em alguns países os compósitos madeira-concreto são muito populares, porque a união de uma camada de concreto na região comprimida e a madeira na região tracionada permite que as melhores qualidades desses dois materiais possam ser aproveitadas. De fato, o concreto é usado somente na compressão, obtendo-se sua melhor performance em termos de resistência e rigidez e a madeira é usada na tração, eliminando-se o concreto tracionado. Dessa maneira, é possível obter uma seção transversal estruturalmente eficiente, rígida e leve ao mesmo tempo. Ceccotti (1995) afirma que, desse modo, a capacidade de carga de um piso de madeira tradicional pode ser dobrada e sua rigidez transversal melhorada em torno de três ou quatro vezes.

Quando comparadas às vigas de madeira e concreto, com os materiais considerados isoladamente, ou seja, sem qualquer interação, a consideração da interação entre a madeira e o concreto resulta em um aumento de resistência à flexão em pelo menos $40 \%$, e os acréscimos na rigidez atingem $200 \%$ ou mais (DAVIDS, 2001).

$\mathrm{O}$ sistema misto madeira-concreto tem sido empregado com sucesso, principalmente nas readequações de edificações antigas da Europa, visando a melhorar as deficiências apresentadas pelas construções de alvenaria com piso de madeira. Além 
dos problemas de isolamento acústico, Ceccotti (1995) salienta que a colocação da laje de concreto sobre um piso de estrutura de madeira torna a edificação muito rígida, o que é conveniente para manter sua forma em caso de abalos sísmicos. A Figura 3 mostra um pormenor da adição da camada de concreto em uma edificação de alvenaria com piso de madeira.

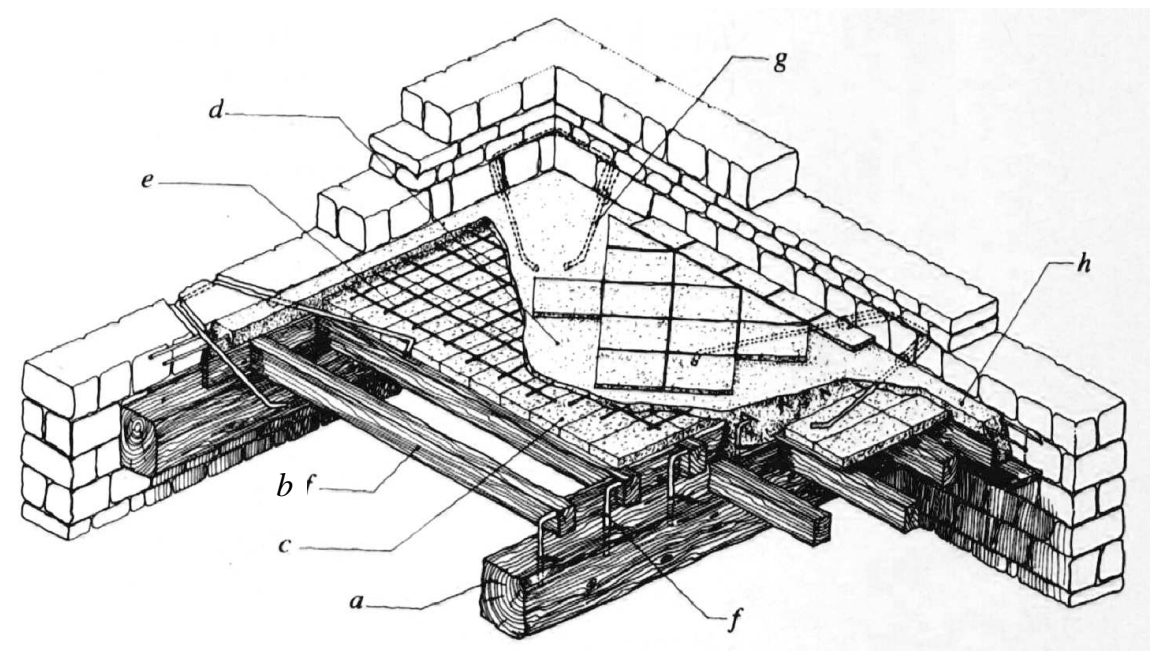

$$
\begin{aligned}
& \quad \text { Legenda: } \\
& \text { a - vigas principais } \\
& \text { b - vigas secundárias } \\
& \mathrm{c} \text { - cerâmica } \\
& \mathrm{d} \text { - laje de concreto } \\
& \mathrm{e} \text { - armadura em malha } \\
& \mathrm{f} \text { - conectores metálicos } \\
& \text { colados com epóxi na } \\
& \text { madeira } \\
& \mathrm{g} \text { - conectores metálicos } \\
& \text { entre alvenaria } \mathrm{e} \\
& \text { concreto } \\
& \mathrm{h} \text { - viga de concreto } \\
& \text { armado no contorno }
\end{aligned}
$$

Figura 3. Detalhe de fixação de laje de concreto em piso de madeira.

Fonte: Ceccotti (1995)

Podem ser salientadas, ainda, as seguintes vantagens para o sistema misto madeira-concreto:

- Aumento do amortecimento vibracional: isso significa que as verificações relativas aos estados limites de utilização devidas às vibrações são mais facilmente satisfeitas.

- A rigidez no plano pode ser considerada infinita: em outras palavras, o piso torna-se tão rígido que é capaz de manter a sua forma e, conseqüientemente, a forma global do edifício.

- Melhor isolamento acústico: o acréscimo de massa do piso, quando comparado com um piso de madeira tradicional, traz benefícios para os ruídos transmitidos pelo ar; para ruídos de impacto, o isolamento acústico é melhorado, em relação a um piso totalmente de concreto, devido ao maior amortecimento.

- Benefícios em situações de incêndio: a camada superior de concreto constitui-se em uma barreira eficiente contra a propagação do fogo, o que aumenta a resistência ao fogo em comparação com um piso totalmente em madeira. Outrossim, as peças inferiores de madeira são mais resistentes ao fogo que as correspondentes peças feitas de aço ou de concreto armado.
- Agilidade construtiva e a madeira ainda pode atuar como forro ou receber acabamentos.

As estruturas mistas requerem um sistema de ligação entre os componentes, o qual deve assegurar a transferência dos esforços de cisalhamento horizontal e, também, seja capaz de evitar o desprendimento vertical entre as partes. Esse sistema pode ser do tipo rígido ou flexível. A ligação rígida pode ser obtida, por exemplo, pela aplicação de um adesivo epóxi na superfície de contato entre os dois materiais, impedindo os deslocamentos entre as peças. Já o outro sistema pode ser obtido por conectores metálicos, como pregos, parafusos, chapas metálicas, anéis metálicos e pinos obtidos a partir de barras lisas de aço ou de aço trefilado. O uso dos conectores metálicos facilita a execução da ligação dos dois materiais e é mais econômico que o adesivo epóxi, afirma Soriano (2001).

Murthy (1984) cita sua experiência com esse método na National University of Singapore, em que foram utilizados parafusos horizontais para formar compósitos de madeira-concreto nos pisos e escadas do edifício. Ahmadi e Saka (1993) relatam o uso de pregos de alta resistência, como conectores, para 
resistirem ao cisalhamento em pisos de madeiraconcreto na região do Golfo Pérsico. Os ensaios com as vigas produzidas mostraram que a capacidade de carga da estrutura mista duplicou em relação a uma não composta e as flechas no meio do vão foram reduzidas em 1/5. Meierhofer (1993) pormenoriza um sistema de construção europeu de madeira e concreto e cita a construção de setenta projetos usando esse sistema, incluindo uma capa de concreto em um piso de madeira existente para melhorar sua rigidez e resistência.

O custo de um piso madeira-concreto é competitivo, quando comparado com um piso totalmente de concreto. Ceccotti (1995) ressalta que não é somente a relação custo $/ \mathrm{m}^{2}$ do produto em si que deve ser levada em conta, pois há outros fatores que contribuem para a economia no resto da estrutura e no canteiro de obras (ex. rapidez na execução, menor quantidade de fôrmas para concreto e diminuição de contraventamentos, redução nas fundações devido à diminuição do peso da estrutura, etc).

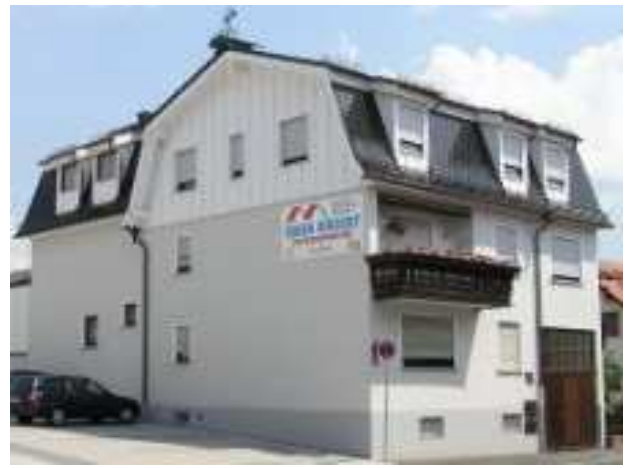

(a)

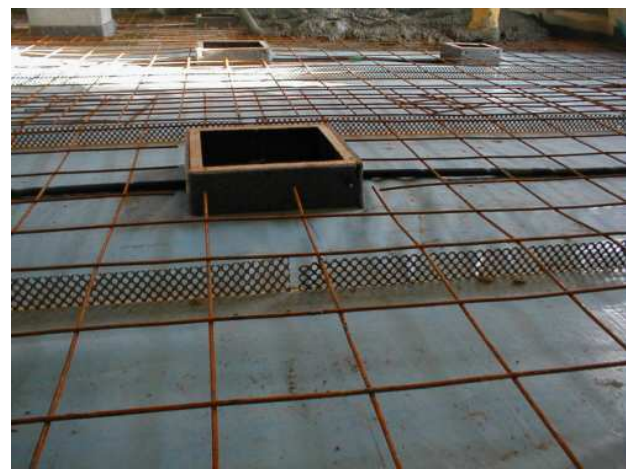

(c)
Em algumas regiões da Europa, a aplicação do sistema misto madeira-concreto é uma realidade, tanto nas revitalizações de antigas construções como nas novas edificações. As Figuras $4 a, 4 b, 4 c$ e $4 d$ mostram uma edificação, em Haibach, Alemanha, que em 2003 passou por um processo de readequação, empregando-se o sistema misto madeira-concreto. A empresa patenteou o sistema misto de madeiraconcreto utilizado nessa readequação, por trabalhar com um conector contínuo constituído por uma chapa metálica perfurada, que se observa na Figura 4c, colocado em aberturas feitas nas peças de madeira, conforme Figura $4 \mathrm{~b}$. O concreto empregado tem espessura mínima de $70 \mathrm{~mm}$, pertencendo no mínimo à classe C20 européia, e recebe uma malha de aço, mostrada na Figura 4c, segundo informações da empresa alemã HBV-Systems (2006). Pode ser executado sobre estrutura de madeira serrada, de MLC ou ainda de outros produtos estruturais derivados da madeira.

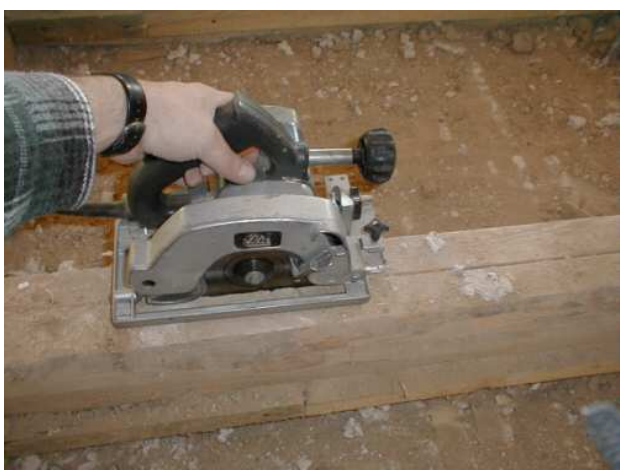

(b)

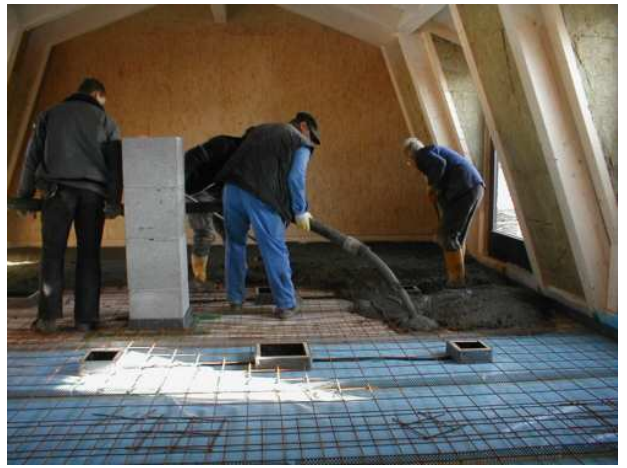

(d)

Figura 4. Edificação em Haibach. (a) Vista externa. (b) Abertura para colagem dos conectores.

(c) Sistema pronto para a concretagem. (d) Concretagem.

Fonte: HBV Systems (2006) 
No Brasil, diversos pesquisadores vêm estudando esse tema, a partir da década de 70. Podem ser mencionados os trabalhos desenvolvidos por Magalhães e Chahud (1998); Souza, Chahud e Magalhães (1998); Matthiesen (2000); Moreira e Chahud (2002) e Mantilla Carrasco et al. (2004), que investigaram o sistema e, especialmente, o sistema de conexão entre a madeira e o concreto. Soriano (2001) realizou investigações experimentais com a associação de vigas de madeira serrada e laje de concreto e concluiu que, na estrutura mista de madeira-concreto, a flecha pode deixar de ser a condição principal limitante para o carregamento. Isso se deve à grande rigidez apresentada pela seção mista que, no caso da flecha limite, resultou numa carga quatro vezes superior àquela prevista para a seção de madeira estudada.

\section{Conclusões}

As estruturas das construções inseridas nas áreas tombadas pelo patrimônio da humanidade têm como denominador comum serem de madeira. Por interagirem com o meio em que estão inseridas, boa parte delas acabam deterioradas. Dentre as técnicas consolidadas para a reabilitação de estruturas de madeira estão a substituição das peças danificadas e/ou a solidarização de elementos que complementem a sua capacidade mecânica. A colagem de fibras naturais ou sintéticas, impregnadas com resinas poliméricas, é uma técnica que vem sendo estudada e os resultados são animadores. As fibras naturais são abundantes, biodegradáveis e têm baixo custo, quando comparadas às fibras sintéticas. Essas últimas, porém, apresentam elevado desempenho mecânico e regularidade dimensional, o que as credencia como candidatas à elaboração de compósitos avançados.

Indubitavelmente, a MLC tem-se mostrado uma alternativa propícia para um melhor aproveitamento dos recursos florestais brasileiros. Pesquisas mostram que a resistência da MLC pode ser melhorada com a adição de fibras (de vidro ou de carbono) na região tracionada, resultando no aumento da confiabilidade do material e uma redução de $30 \%$ a $40 \%$ no volume de madeira utilizada. Acrescenta-se, ainda, que o reforço aplicado a uma razão de $2 \%$ a $3 \%$, pode aumentar a resistência à flexão de vigas de MLC em mais de $100 \%$.

A adição de fibras na face tracionada das peças de madeira garante uma excelente performance na flexão, mas o ganho em termos de rigidez é modesto. Assim sendo, as peças de madeira reforçadas com fibras apresentam grande deformabilidade. Uma das possibilidades de modificação desse comportamento consiste em adotar as estruturas mistas de madeiraconcreto, que se vêm revelando uma alternativa promissora, especialmente nos aspectos de durabilidade, rigidez e conforto acústico. Com a utilização dessa técnica, estudos mostram que a capacidade de carga de um piso de madeira tradicional pode ser dobrada e sua rigidez transversal melhorada em torno de três ou quatro vezes. Essa solução também é aplicada com muito sucesso nas readequações de antigas construções européias, especialmente nos casos em que há aumento de carga decorrente de uma nova utilização da edificação.

\section{Agradecimentos}

Os autores agradecem ao Conselho Nacional de Desenvolvimento Científico e Tecnológico (CNPq) pelo financiamento deste trabalho.

\section{Referências}

AHMADI, B. H.; SAKA, M. P. Behaviour of composite timber-concrete floors. Journal of Structural Engineering, ASCE, v.119, n.10, p.31113130, nov. 1993.

ALVIM, R. C. et al. Piso misto de madeira-concreto para uma edificação residencial. In: ENCONTRO BRASILEIRO EM MADEIRAS E EM ESTRUTURAS DE MADEIRA, 7., 2000, São Carlos. Anais... São Carlos: Escola de Engenharia de São Carlos/USP, 2000. CD-ROM. 
AMERICAN SOCIETY FOR TESTING AND MATERIALS. ASTM D3878: standard terminology for composite materials. Philadelphia, 2004. 5p.

CARVALHO, R. F. Compósitos de fibras de sisal para uso em reforço de estruturas de madeira. 2005. Tese (Doutorado em Ciência e Engenharia de Materiais) - Universidade de São Paulo, São Carlos.

CECCOTTI, A. Timber-concrete composite structures. In: BLASS, H. J. et al. Timber Engineering - STEP 2 (Structural Timber Education Programme). Netherlands: Centrum Hout, 1995. p.E13/1-E13/12.

DAGHER, H. J. FRP-reinforced wood in bridge applications. In: RILEM SYMPOSIUM TIMBER ENGINEERING, 1., 1999, Stockholm. Anais... Stockholm, Sweden, 1999. p.591-598.

High-performance wood composites for construction. In: ENCONTRO BRASILEIRO EM MADEIRAS E EM ESTRUTURAS DE MADEIRA, 7., 2000, São Carlos. Anais... São Carlos: Escola de Engenharia de São Carlos/USP, 2000. CD-ROM.

DAVIDS, W. G. Nonlinear analysis of FRP-glulamconcrete beams with partial composite action. Journal of Structural Engineering, ASCE, v.127, n.8, p.967-971, aug. 2001.

FIORELLI, J. Utilização de fibras de carbono e de fibras de vidro para reforço de vigas de madeira. 2002. Dissertação (Mestrado em Ciência e Engenharia de Materiais) - Escola de Engenharia de São Carlos, Universidade de São Paulo, São Carlos.

Estudo teórico e experimental de vigas de madeira laminada colada reforçadas com fibra de vidro. 2005. Tese (Doutorado em Ciência e Engenharia de Materiais) - Escola de Engenharia de São Carlos, Universidade de São Paulo, São Carlos.
GELFI, P.; GIURIANI, E. Stud shear connectors in wood-concrete composite beams. In: RILEM SYMPOSIUM ON TIMBER ENGINEERING, 1., 1999, Cachan, France. Proceedings... Cachan, 1999. p.245-254.

GUTKOWSKI, R. M. Tests and analysis of mixed concrete-wood beams. In: INTERNATIONAL WOOD ENGINEERING CONFERENCE, 1996, New Orleans, USA. Proceedings... New Orleans: Lousiana State University, 1996. p.436-442.

HBV-Systems. Innovative Wood-ConcreteComposite Constructions. Disponível em: <http:// www.hbv-systeme.de/index_e.htm>. Acesso em: 25 abr. 2006.

MAGAlHÃES, L. N.; CHAHUd, E. Análise experimental de vigas $\mathrm{T}$ compostas por madeira/ concreto. In: ENCONTRO BRASILEIRO EM MADEIRAS E EM ESTRUTURAS DE MADEIRA, 6., 1998, Florianópolis. Anais... Florianópolis: Universidade Federal de Santa Catarina, 1998. v.2, p.266-276.

MANTILLA CARRASCO, E. V. et al. Viga mista de madeira laminada colada de Eucalyptus Grandis e concreto armado - uma avaliação experimental e numérica. In: ENCONTRO BRASILEIRO EM MADEIRAS EEM ESTRUTURAS DE MADEIRA, 9., 2004, Cuiabá. Anais... Cuiabá: Universidade Federal de Mato Grosso, 2004. CD-ROM.

MATTHIESEN, J. Estudo da ligação madeiraconcreto com parafusos autoatarrachante comerciais. In: ENCONTRO BRASILEIRO EM MADEIRAS E EM ESTRUTURAS DE MADEIRA, 7., 2000, São Carlos. Anais... São Carlos: Escola de Engenharia de São Carlos/USP, 2000. CD-ROM.

MEIERHOFER, U. A timber/concrete composite system. Structural Engineering International, Zurich, v.2, p.104, 1993. 
MOREIRA, L. F. N.; CHAHUD, E. Vigas T compostas madeira/concreto. In: ENCONTRO BRASILEIRO EM MADEIRAS E EM ESTRUTURAS DE MADEIRA, 8., 2002, Uberlândia. Anais... Uberlândia: Universidade Federal de Uberlândia, 2002. CD-ROM.

MURTHY, C. K. Timber-concrete composites for low cost housing. Housing Science, v.8, n.2, p.209215, 1984.

NATTERER, J. et al. Composite wood-concrete floors for multi-story buildings. In: INTERNATIONAL WOOD ENGINEERING CONFERENCE, 1996, New Orleans, USA. Proceedings... New Orleans: Lousiana State University, 1996. p.431-435.

NITA, C. Utilização de pozolanas em compósitos de cimento reforçados com fibras de celulose e PVA. 2006. Dissertação (Mestrado em Engenharia) - Escola Politécnica, Universidade de São Paulo, São Paulo.

PINCUS, G. Bonded wood-concrete T-beams. Journal of Structural Division, ASCE, v.95, n.10, p.2265-2279, 1969.

SORIANO, J. Estruturas mistas em concreto e em madeira: análise de vigas e painéis e aplicações na construção civil. 2001. Tese (Doutorado em Engenharia Agrícola) - Faculdade de Engenharia Agrícola, Universidade Estadual de Campinas, Campinas.

SOUZA, A. J.; CHAHUD, E.; MAGALHÃES, L. N. Estudo da correlação entre o comportamento de corpos-de-prova de cisalhamento e vigas compostas madeira/concreto. In: ENCONTRO BRASILEIRO EM MADEIRAS E EM ESTRUTURAS DE MADEIRA, 6., 1998, Florianópolis. Anais... Florianópolis: Universidade Federal de Santa Catarina, 1998. v.2, p.278-285.
TANG, B. Fiber reinforced polymer composites applications in USA DOT - Federal Highway Administration. In: FIRST KOREA/U.S.A. ROAD WORKSHOP, 1997, Washington. Proceedings... Washington, jan. 1997.

TRIANTAFILlOU, T. C.; DESKOVIC, N. Prestressed FRP sheets as external reinforcement of wood members. Journal of Structural Engineering, ASCE, v.118, n.5, p.1270-1284, may 1992. 